\title{
BMJ Open Pathways to psychiatric care and factors associated with delayed help-seeking among patients with mental illness in Northern Ethiopia: a cross- sectional study
}

\author{
Senait Teshager, ${ }^{1}$ Habtamu Kerebih (D) ,2 Hailemariam Hailesilassie, ${ }^{3}$ \\ Mubarek Abera $^{3}$
}

To cite: Teshager S, Kerebih $\mathrm{H}$, Hailesilassie $\mathrm{H}$, et al. Pathways to psychiatric care and factors associated with delayed help-seeking among patients with mental illness in Northern Ethiopia: a crosssectional study. BMJ Open 2020;10:e033928. doi:10.1136/ bmjopen-2019-033928

- Prepublication history for this paper is available online. To view these files, please visit the journal online (http://dx.doi. org/10.1136/bmjopen-2019033928).

Received 29 August 2019 Revised 27 February 2020 Accepted 02 April 2020

\section{Check for updates}

(C) Author(s) (or their employer(s)) 2020. Re-use permitted under CC BY-NC. No commercial re-use. See rights and permissions. Published by BMJ.

${ }^{1}$ Department of Psychiatry, Ayder Comprehensive Specialized Hospital, Mekele, Northern Ethiopia, Ethiopia

2Department of Psychiatry,

School of Medicine, College of Medicine and Health Sciences, University of Gondar, Gondar,

Ethiopia

${ }^{3}$ Department of Psychiatry, Faculty of Medicine, Institute of Health, Jimma University, Jimma, Ethiopia

Correspondence to Habtamu Kerebih; habtishk@gmail.com

\section{ABSTRACT}

Objective This study aimed to assess pathways to psychiatric care and factors associated with delayed helpseeking among patients with mental illness in Northern Ethiopia using the WHO Pathway Study Encounter Form. Design A cross-sectional study design was used. Setting Data were collected using face-to-face interview from patients with various diagnoses of mental illness attending outpatient treatment at Ayder Comprehensive Specialized Hospital in Mekelle City, Tigray, Northern Ethiopia.

Participants Participants who came to attend outpatient treatment during the study period were included in the study using consecutive sampling technique.

Outcome measures Pathways to psychiatric care, delayed psychiatric treatment and factors affecting delayed psychiatric treatment.

Results The median duration from problem onset to contact with first care provider was 4 weeks, whereas contact with modern psychiatric services was 52.0 weeks. Study participants who were single (adjusted OR $(A O R)=2.91$, $95 \% \mathrm{Cl} 1.19$ to 7.11 ), divorced ( $\mathrm{AOR}=3.73,95 \% \mathrm{Cl} 1.33$ to 10.49) and who perceived mental illness as shameful (AOR=3.29, 95\% $\mathrm{Cl} 1.15$ to 9.41) had delayed treatmentseeking behaviour, whereas participants with no history of substance use (AOR=0.43, 95\% $\mathrm{Cl} 0.20$ to 0.92) were less likely to have delayed treatment-seeking behaviour. Conclusions There is significant delay in seeking modern psychiatric treatment. Religious healers were the first source of help for mental illness. Majority of the respondents described that mental illness was due to supernatural causes. Stigma and lack of awareness about where treatment is available were barriers to seeking appropriate care.

\section{BACKGROUND}

Mental illness is associated with high levels of chronicity, comorbidity and premature mortality. ${ }^{12}$ This is because onset of firstepisode mental illness usually happens at an early age. ${ }^{3}$ However, most people with illnesses do not get early psychiatric treatment. ${ }^{4}$ Studies
Strengths and limitations of this study

- This study was conducted based on the pathway encounter form developed by a WHO collaborative study which is important in collecting data on the number of patients with mental disorders seeking services from both formal and informal sectors.

- The study helps to identify major sources of consultation used by patients for psychiatric care.

- This is the first study on the pathway to psychiatric care in the northern part of Ethiopia, with $100 \%$ response rate maintained.

- This study was conducted at a tertiary hospital among patients with severe mental illness and might not be generalised to patients who do not receive mental health services and to those with common mental disorders following treatment at primary healthcare settings.

- Recall bias regarding onset of illness could lead to over-reporting and under-reporting of the duration of untreated mental illness.

indicated that traditional and faith healers are the first sources of help for majority of patients. ${ }^{45}$ This is related to patients' knowledge about the causes and treatments of the illness and their awareness of available services. ${ }^{6}$ These factors lead to prolonged duration of untreated mental illness (DUMI), with its adverse consequences including poorer response to psychotropic medications, symptom control and long-term prognosis with more relapses. As a result, people with mental illness (PMI) develop poor quality of life and compromise their social, personal and occupational functioning. Empirical studies have shown that DUMI averages 1-2 years, and the average DUMI is even longer in developing nations. The reasons for which are yet to be explored in studies on pathways to care service. ${ }^{7}$ Therefore, reducing DUMI has 
become the primary aim of modern psychiatric services for patients with mental illness. ${ }^{8}$ This can be achieved by identifying patients' pathways to different sources of help and the factors that delay psychiatric treatment. ${ }^{6}$ Pathway to care is a comprehensive and systematised clarification of sources of care used by patients before seeking help from mental health professionals. It is a rapid and reasonable method of studying the help-seeking behaviour of mentally ill patients and their family. ${ }^{9}$

Descriptive studies from different countries indicated that a large number of patients do not present directly to mental health professionals. They adopt paths which traverse through many agencies. ${ }^{10}$ Results of studies indicated mixed findings with regard to the first source of help among PMI. While it has been reported that faith healers and non-psychiatrist allopath care providers were the first to be consulted, ${ }^{61112}$ in other studies psychiatrists followed by traditional healers and general practitioners were the first consulted. ${ }^{13-16}$ Results from two previous Ethiopian studies also presented different findings. One of the studies, conducted in the capital city of Addis Ababa, in a specialised mental health hospital, showed that $41 \%$ of patients with new episodes of neuropsychiatric disorders directly consulted a psychiatrist. About one-third $(30.9 \%)$ of patients sought care from priests, holy water or the church. ${ }^{10}$ In contrast, the second study, which was conducted in Southwest Ethiopia, in a psychiatric clinic under a general hospital set-up, reported that half of the patients sought traditional treatment from either a religious healer $(30.2 \%)$ or a herbalist $(20.1 \%)$ before they came to the hospital for psychiatric care. ${ }^{17}$

The median duration of untreated illness is affected by the paths taken by patients to arrive at hospitals for psychiatric care. A study done in different countries revealed that people with mental disorders seek treatment after 6 months and more from onset of their illness. ${ }^{6}{ }^{18}$ In Asianbased studies, where most of the initial sources of help reported were traditional or religious care providers, the median duration of untreated illness greatly varies. In a study from Iran, the duration of untreated psychosis (DUP) and pathways to care in patients with first-episode psychosis showed a median DUP of 11 weeks, with a mean of 52 weeks, whereas it was 64 weeks and 10.5 weeks from the results of studies in Pakistan and Bangladesh, respectively. ${ }^{13-15}$ In a Nigerian study, the mean and median DUP were $72.80 \pm 75.7$ and 52 weeks, respectively. ${ }^{11}$ In Ethiopian studies, the median delay between onset of illness and arrival at the psychiatric hospital was 38 weeks, ${ }^{10}$ while the median duration of symptoms of mental illness before contact with modern mental health service was 52.1 weeks. ${ }^{17}$ Consulting healers first might lead to prolonged pathway to psychiatric care and is a possible obstacle to early detection, identification and intervention. ${ }^{615} 18$

It was indicated that subjects who chose to use psychiatric services as first point of care were more likely to be younger, unmarried, unemployed and better educated ${ }^{61017}$ Patients who reported financial difficulties ${ }^{14}$ and who were diagnosed with schizophrenia and substance use disorders initially sought psychiatric care from non-psychiatric treatment facilities or centres before seeking care at public psychiatric hospitals. ${ }^{16}$ The stigma associated with the illness and the knowledge and beliefs about the cause of mental illness were found to affect preferences for sources of help among patients and caregivers. ${ }^{12} 14$

However, in the northern part of Ethiopia, no scientific data are available indicating pathways to psychiatric care service. Therefore, this study was conducted with the aim to assess the pathway to psychiatric care service and the associated factors that delay help-seeking among PMI. This type of study is very crucial to identify contributing factors to delayed psychiatric care and provide interventions for better treatment prognosis and outcome.

\section{METHODS \\ Study design and setting}

A hospital-based, cross-sectional study was conducted at Ayder Comprehensive Specialized Hospital, Mekelle City, Northern Ethiopia from May to June 2017. The Ayder Comprehensive Specialized Hospital commenced rendering its referral and non-referral services in 2008. The hospital provides services to a population of eight million people in its catchment areas of Tigray, Afar and the northeastern parts of the Amhara national regional states. It provides inpatient and outpatient services to all age groups. The psychiatry unit has 18 beds, and approximately 850 patients receive outpatient services every month. The psychiatry unit is the only clinical department which receives patients without referral and with referrals from all directions of the catchment area.

\section{Participant selection}

Sample size was determined using single population proportion formula assuming that $50 \%$ of the participants will seek early treatment at $95 \% \mathrm{CI}$ and $5 \%$ margin error. Considering a $10 \%$ non-response rate, a total of 423 adult patients with mental illnesses were selected. Consecutive sampling method was used to select the study participants until the required sample size was achieved.

\section{Patient and public involvement \\ No patients were involved.}

\section{Data collection and measurements}

Data were collected using structured, intervieweradministered questionnaires prepared in local languages (Amharic and Tigre languages). Pathways to psychiatric care were assessed using the WHO Encounter Form. This questionnaire documents the carer from whom help is initially sought (the first pathway contact), and then the next carer (second pathway contact), the third carer (third pathway contact) and finally the fourth carer (fourth pathway contact) ${ }^{19}$ Treatment delay was measured using the median time interval in weeks from problem onset to contact with psychiatric services. To sort significant delay for seeking mental health treatment, 52.1 weeks' median 
Table 1 Sociodemographic characteristics of study participants at Ayder Comprehensive Specialized Hospital

\begin{tabular}{|c|c|c|c|}
\hline Variables & Responses & Frequencies & Percentages \\
\hline \multirow[t]{2}{*}{ Residence } & Rural & 141 & 33.3 \\
\hline & Urban & 282 & 66.7 \\
\hline \multirow[t]{4}{*}{ Age } & $18-30$ & 217 & 51.3 \\
\hline & $31-40$ & 130 & 30.7 \\
\hline & $41-50$ & 59 & 13.9 \\
\hline & $51-60$ & 17 & 4.0 \\
\hline \multirow[t]{2}{*}{ Sex } & Male & 226 & 53.4 \\
\hline & Female & 197 & 46.6 \\
\hline \multirow[t]{4}{*}{ Marital status } & Married & 104 & 24.6 \\
\hline & Single & 239 & 56.5 \\
\hline & Divorced & 63 & 14.9 \\
\hline & Widowed & 17 & 4.0 \\
\hline \multirow[t]{4}{*}{ Religion } & Orthodox & 342 & 80.9 \\
\hline & Muslim & 66 & 15.6 \\
\hline & Catholic & 8 & 1.9 \\
\hline & Protestant & 7 & 1.7 \\
\hline \multirow[t]{5}{*}{ Ethnicity } & Tigray & 392 & 92.7 \\
\hline & Amhara & 15 & 3.5 \\
\hline & Oromo & 6 & 1.4 \\
\hline & Afar & 9 & 2.1 \\
\hline & SNNP & 1 & 0.2 \\
\hline \multirow[t]{6}{*}{ Education } & Illiterate & 109 & 25.8 \\
\hline & $\begin{array}{l}\text { Can read and } \\
\text { write }\end{array}$ & 18 & 4.3 \\
\hline & Primary school & 107 & 25.3 \\
\hline & High school & 102 & 24.1 \\
\hline & Diploma & 40 & 9.5 \\
\hline & $\begin{array}{l}\text { Degree and } \\
\text { above }\end{array}$ & 47 & 11.1 \\
\hline \multirow[t]{8}{*}{ Occupation } & Jobless & 205 & 48.5 \\
\hline & Daily labourer & 25 & 5.9 \\
\hline & Farmer & 46 & 10.9 \\
\hline & $\begin{array}{l}\text { Private } \\
\text { business }\end{array}$ & 49 & 11.6 \\
\hline & Prisoner & 2 & 0.5 \\
\hline & Student & 33 & 7.8 \\
\hline & Housewife & 23 & 5.4 \\
\hline & Civil servant & 40 & 9.5 \\
\hline \multirow[t]{3}{*}{ Family size } & $1-3$ & 235 & 55.6 \\
\hline & $4-8$ & 165 & 39 \\
\hline & $>8$ & 23 & 5.4 \\
\hline
\end{tabular}

SNNP, Southern Nations, Nationalities, and Peoples' Region.

duration was taken as a reference point from a study conducted in Southwest Ethiopia. ${ }^{17}$ Therefore, individuals who sought mental health treatment from psychiatric hospitals after 52.1 weeks from the first onset of illness were categorised as delayed treatment-seeking and before
52.1 weeks as early treatment-seeking for psychiatric care. Data were collected by eight trained BSc Psychiatry nurses using face-to-face interviews.

\section{Data processing and analysis}

The collected data were coded after checking for their completeness and were then entered into EpiData V.3.1.3, cleaned and exported to IBM SPSS Statistics V.20 for Windows for further analysis. Descriptive statistics were computed for continuous variables. For categorical variables, bivariate analyses were performed to nominate candidate variables for multivariate logistic regression analysis. Then, variables with $p$ value of 0.25 and below were fitted to multivariate logistic regression analysis model to assess variables that have associations with the outcome variable and with $95 \%$ CI to control for confounding. The strength of association was measured using adjusted OR (AOR), and the level of statistical significance was declared at $p$ value less than 0.05 .

\section{RESULTS}

\section{Sociodemographic characteristics of study participants}

Data were collected from 423 study participants with $100 \%$ response rate. Of the study participants, $53.4 \%$ were male. The mean age was $32.48(\mathrm{SD} \pm 9.33)$ years, with minimum and maximum age of 18 and 60 years, respectively. About half $(48.5 \%)$ of the participants were jobless and a quarter $(25.8 \%)$ were illiterate (table 1$)$.

\section{Sources of referral for first contact with psychiatric care and} distribution of medically diagnosed mental illnesses

With regard to first contact with psychiatric care, majority (252, 59.6\%) of participants sought treatment for their illness on advice of family members or relatives, followed by former patients $(119,28.1 \%)$. Of the study participants, $107(25.3 \%)$ came with a referral letter. Nearly two-thirds $(268,63.4 \%)$ had follow-up, whereas $155(36.6 \%)$ were new patients. This study indicated that the time interval from onset of symptom to first contact with psychiatric care was not normally distributed. The minimum and maximum time intervals to seek treatment were 0.1 and 1560 weeks, respectively. Outliers with a very long delay were present. Therefore, the median rather than mean duration was used. The median duration from problem onset to contact with modern psychiatric services was 52 weeks, with an IQR of 140 weeks. The time interval to receiving care was early for 247 (58.4\%) and delayed for 176 (41.6\%) study participants. Based on diagnostic and statistical manual of mental disorders fourth edition, text revision (DSM-IV-TR) diagnosis, $182(43 \%)$ were diagnosed with schizophrenia (table 2).

\section{Pathways to psychiatric care}

Of the study participants, $302(71.4 \%)$ sought help from religious healers the first time, $95(22.5 \%)$ sought help directly from a psychiatric service and 11 (2.6\%) from traditional healers (see figure 1 and table 3 ). The main 
Table 2 Distribution of psychiatric care for mental illness among patients attending outpatient treatment at Ayder Comprehensive Specialized Hospital in 2017 ( $\mathrm{N}=423)$

\begin{tabular}{|c|c|c|c|}
\hline Variables & Responses & Frequencies & Percentages \\
\hline \multirow{2}{*}{ Who suggested where to sought care from } & Former patient & 119 & 28.1 \\
\hline & Others $^{*}$ & 20 & 4.7 \\
\hline Come with referral letter & No & 316 & 74.7 \\
\hline \multirow[t]{2}{*}{ History of mental healthcare service } & Yes & 268 & 63.4 \\
\hline & No & 155 & 36.4 \\
\hline \multirow[t]{2}{*}{ Time interval to receiving care } & Early (<52 weeks) & 247 & 58.4 \\
\hline & Delayed (>52 weeks) & 176 & 41.6 \\
\hline \multirow{4}{*}{ Diagnosis based on DSM-TR } & MDD & 85 & 20.1 \\
\hline & Epilepsy & 6 & 1.4 \\
\hline & Anxiety & 16 & 3.8 \\
\hline & Others $†$ & 9 & 2.1 \\
\hline
\end{tabular}

*Others include health professionals, neighbours and work mate. tOthers include sleep, somatoform disorders and PTSD.

DSM-IV-TR, Diagnostic and Statistical Manual of Mental Disorders, Fourth Edition, Text Revision; MDD, major depressive disorder; PTSD, post traumatic stress disorder.

sources of information on where to get help for their illness were family/relatives $(339,80.1 \%)$, the patient himself $(47,11 \%)$ and former patients $(18,4.2 \%)$. The main problems presented were aggressive behaviour (181, 42.8\%), suicidal behaviour $(49,11.6 \%)$, functional impairment $(95,22.5 \%)$ and worsening illness (87, $20.6 \%$ ) (table 3$)$.

In the second point of contact with non-psychiatric service, of the remaining 328 study participants, $6(1.8 \%)$ sought help from religious healers, 55 (16.8\%) from

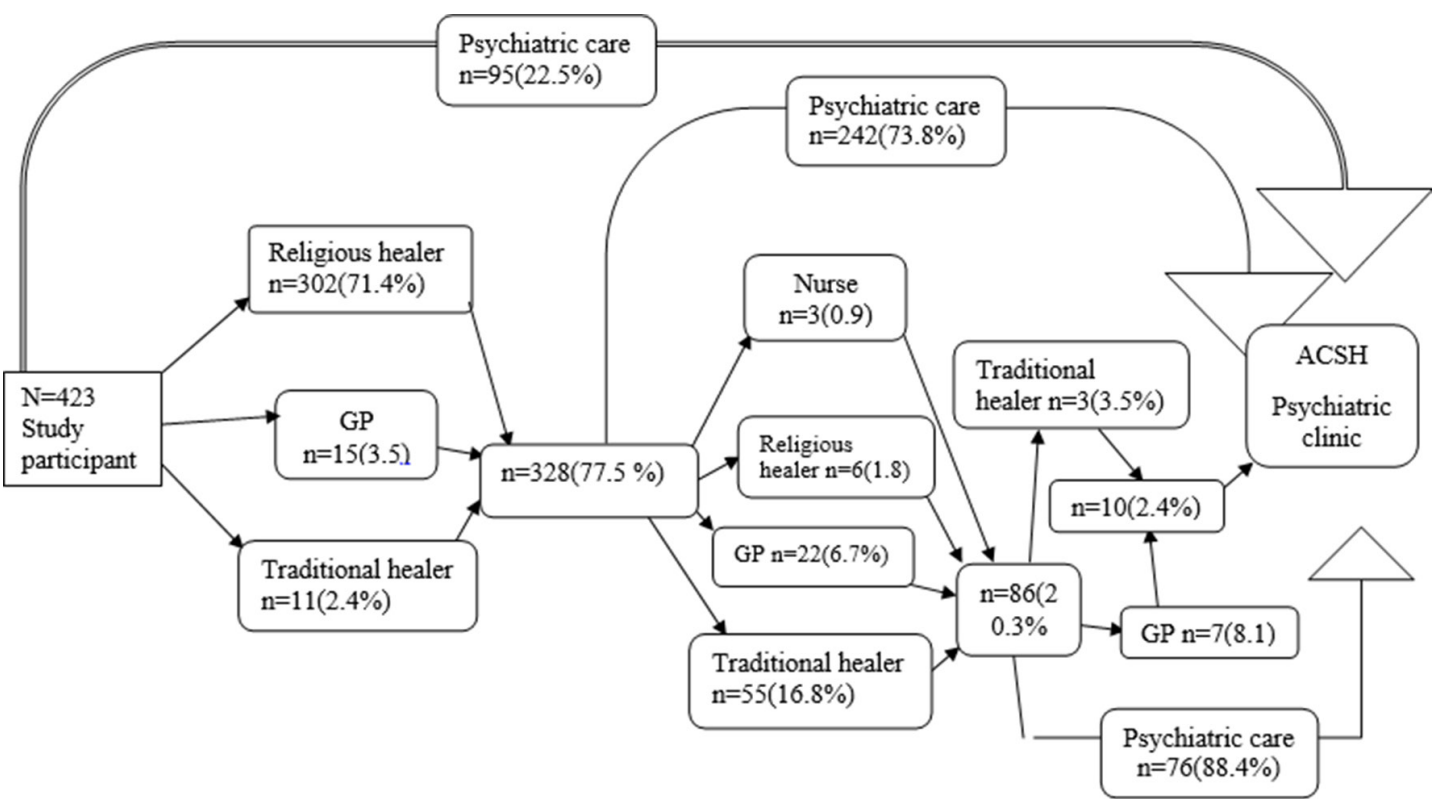

Figure 1 Pictorial representation of pathways to psychiatric care among 423 patients at the ACSH psychiatric clinic. ACSH, Ayder Comprehensive Specialized Hospital; GP, general practitioner. 
Table 3 Distribution of first contact of care among patients at Ayder Comprehensive Specialized Hospital in 2017 ( $N=423$ )

\begin{tabular}{|c|c|c|c|}
\hline Variables & Responses & Frequencies & Percentages \\
\hline \multirow[t]{3}{*}{ Where did you go to seek treatment? } & Religious leader & 302 & 71.4 \\
\hline & Traditional healer & 11 & 2.6 \\
\hline & Psychiatric service & 95 & 22.5 \\
\hline \multirow[t]{5}{*}{ Who suggested to seek care? } & Patient himself & 47 & 11 \\
\hline & Friends & 10 & 2.4 \\
\hline & Neighbour & 8 & 1.9 \\
\hline & Former patient & 18 & 4.3 \\
\hline & Health professional & 1 & 0.2 \\
\hline \multirow[t]{2}{*}{ What was the main problem? } & Aggressive behaviour & 181 & 42 \\
\hline & Worsening illness & 87 & 20.6 \\
\hline \multirow[t]{5}{*}{ What was the main treatment? } & Religious/holy water & 302 & 71.4 \\
\hline & Traditional medicine & 11 & 2.6 \\
\hline & Medication & 10 & 2.4 \\
\hline & Psychiatric service & 95 & 22.5 \\
\hline & Other $^{\star}$ & 5 & 12.2 \\
\hline
\end{tabular}

${ }^{*}$ Other includes the main treatment presented on referral.

traditional healers, $22(6.7 \%)$ from general practitioners, 3 $(0.9 \%)$ from community nurses and $242(73.8 \%)$ contacted modern psychiatric service. The sources of information on where to get psychiatric service were patients themselves (14, 4.3\%), on advice of family/relatives $(214,65.2 \%)$ and former patients $(70,21.3 \%)$. With regard to the problems presented for help-seeking, $81(24.7 \%)$ were due to aggressive behaviour, $27(8.2 \%)$ due to suicide attempt, 63 $(19.2 \%)$ due to functional impairment and 147 (44.8\%) due to worsening illness.

In the third pathway after contact with non-psychiatric service, of the remaining 86 study participants, 76 $(88.4 \%)$ sought help from psychiatric service, $7(8.1 \%)$ from general practitioners and $3(3.5 \%)$ from traditional healers. With regard to sources of information on where to get service, $44(51.1 \%)$ were from family/ relatives, $31(36 \%)$ from former patients, $7(8.1 \%)$ from health professionals, 2 (2.3\%) from neighbours and $1(1.2 \%)$ on advice of a work mate. With regard to the main problems presented for seeking help, 20 (23.3\%) were due to aggressive behaviour, 5 (5.8\%) due to suicide attempt, $12(14 \%)$ due to functional impairment and $49(57 \%)$ due to worsening illness.

In the fourth pathway, of the remaining 10 study participants, all (100\%) sought help from psychiatric service. With regard to source of information on where to get service, $2(20 \%)$ were from family/relatives, $6(60 \%)$ from former patients and $2(20 \%)$ from health professionals. With regard to the main problem presented for seeking help, 1 (10\%) was due to aggressive behaviour, $1(10 \%)$ due to suicidal behaviour and 8 $(80 \%)$ due to worsening illness.

Perceived cause, severity, stigma and treatment option for mental illness and reasons for delay in treatment-seeking The study participants provided reasons for delay in help-seeking treatment; $41(9.7 \%)$ were due to financial difficulties, $222(52.5 \%)$ did not know where to seek help, which could be due to being new to the environment for PMI coming from Arab countries and being internally displaced from different regions of the country due to intercommunal conflict, and $72(17 \%)$ were due to lack of accessibility of mental health facilities near their area. With regard to perceived causes of mental illness, spiritual possession, evil eye, sinful act, walks around garbage dumps and stress accounted for $124(29.3 \%), 41(9.7 \%), 31(7.3 \%), 38(9 \%)$ and 129 $(30.5 \%)$, respectively. With regard to problems faced in help-seeking, patients responded that it is due to family members not recognising the severity of illness (272, $64.3 \%)$ and to family members feeling ashamed (102, $24.1 \%)$.

Majority $(349,82.5 \%)$ of the study participants responded that mental illness is curable, and almost all $(343,97.4 \%)$ responded mental illness can be treated by modern treatment. The study participants responded that mental illness affects people who are angry and stressed $(244,57.5 \%)$ and people with crisis 
$(58,13.7 \%)$. With regard to perceived severity of mental illness, $260(61.5 \%)$ responded very severe, whereas 16 $(3.8 \%)$ responded less severe. In terms of community perception of mental illness, those who responded were very highly shameful $(86,20.1 \%)$, not as such shameful $(107,25.3 \%)$ and not at all shameful $(102,24.1 \%)$ (table 4).

Table 4 Distribution of patients' perception towards cause, severity, stigma and treatment option for mental illness and reasons for delay in treatment-seeking at Ayder Comprehensive Specialized Hospital, 2017 ( $N=423$ )

\begin{tabular}{|c|c|c|c|}
\hline Variables & Responses & Frequencies & Percentages \\
\hline \multirow[t]{6}{*}{ Reasons for delay in help-seeking } & Distance & 36 & 8.5 \\
\hline & Financial difficulties & 41 & 9.7 \\
\hline & Didn't know where to seek help & 222 & 52.5 \\
\hline & Lack of mental health service & 72 & 17 \\
\hline & Did not believe in modern treatment & 25 & 5.9 \\
\hline & Arrived at an early time & 27 & 6.4 \\
\hline \multirow[t]{8}{*}{ Perceived causes of mental illnesses } & Spiritual possession & 124 & 29.3 \\
\hline & Evil eye & 41 & 9.7 \\
\hline & Family history & 23 & 5.4 \\
\hline & Sinful act & 31 & 7.3 \\
\hline & Pathogen & 5 & 1.2 \\
\hline & Walk around tomb, ash, forest & 38 & 9 \\
\hline & I don’t know & 32 & 7.6 \\
\hline & Stress & 129 & 30.5 \\
\hline \multirow[t]{5}{*}{ Problems faced in help-seeking } & Family didn't recognise severity of the illness & 272 & 64.2 \\
\hline & Family member felt shameful & 102 & 24.1 \\
\hline & Couldn't convince medical staff & 16 & 3.8 \\
\hline & Friends/relatives discourage them & 11 & 2.6 \\
\hline & Didn’t face any problem & 12 & 2.8 \\
\hline \multirow[t]{3}{*}{ Is mental illnesses curable? } & Yes & 349 & 82.5 \\
\hline & I am not sure & 4 & 0.9 \\
\hline & No & 70 & 16.5 \\
\hline \multirow{3}{*}{$\begin{array}{l}\text { Which treatment can be used to treat } \\
\text { mental illness? }\end{array}$} & Modern medicine & 343 & 97.4 \\
\hline & Holy water & 6 & 1.7 \\
\hline & Traditional medicine & 2 & 0.6 \\
\hline \multirow{5}{*}{$\begin{array}{l}\text { Which kinds of people are affected } \\
\text { by mental illnesses? }\end{array}$} & Angry and stressed & 244 & 57.7 \\
\hline & People who use drugs & 44 & 10.4 \\
\hline & People with crisis & 58 & 13.7 \\
\hline & Those who think a lot & 56 & 13.2 \\
\hline & Others $^{*}$ & 21 & 5 \\
\hline \multirow[t]{4}{*}{ Perceived severity of mental illnesses } & Very highly severe & 260 & 61.5 \\
\hline & Highly severe & 96 & 22.1 \\
\hline & Severe & 51 & 12.1 \\
\hline & Less severe & 16 & 3.8 \\
\hline \multirow[t]{5}{*}{ Perception of mental illness } & Very highly shameful & 86 & 20.1 \\
\hline & Highly shameful & 83 & 19.6 \\
\hline & Shameful & 46 & 10.9 \\
\hline & Not as such shameful & 107 & 25.3 \\
\hline & Not at all shameful & 102 & 24.1 \\
\hline
\end{tabular}

*Others include having evil eye and I don't know. 


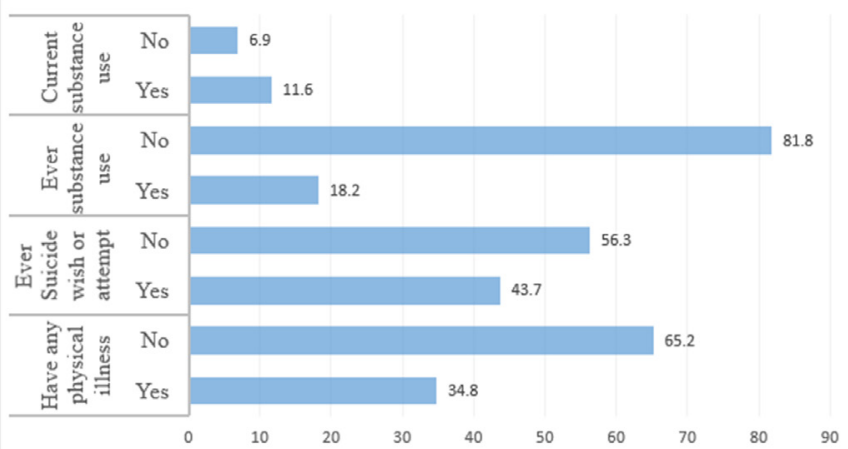

Figure 2 Distribution of physical illnesses/symptoms, substance use and suicidal behaviours. Physical illnesses/ symptoms include diabetes, hypertension, HIV, genitourinary symptoms, headache, fever, weight loss, cough, chest pain, abdominal pain and joint pain. Substances include alcohol, tobacco, khat and cannabis.

\section{Distribution of physical illnesses/symptoms, substance use and suicidal behaviours}

Of the participants, $145(34.8 \%)$ had physical illness. Suicidal behaviours and substance use were high among the participants (figure 2).

\section{Factors associated with delayed contact with modern psychiatric care}

Controlling for other variables, age category was statistically associated with delay in treatment-seeking. Participants aged $31-40$ years were 2.8 times $(\mathrm{AOR}=2.8,95 \% \mathrm{CI}$ 1.4 to 5.59 ) more likely to have delayed modern psychiatric service than the 18-30 years age group. Marital status was statistically associated with delayed psychiatric treatment. Study participants who are single $(\mathrm{AOR}=2.52$, 95\% CI 1.03 to 6.22 ) and divorced (AOR=3.5, 95\% CI 1.25 to 9.81 ) were 2.5 and 3.5 times more likely to have delayed psychiatric treatment than those who are married. Study participants who were jobless were 3.4 times $(\mathrm{AOR}=3.38$, 95\% CI 1.05 to 10.82 ) more likely to have delayed psychiatric treatment than those who were employed. Patients with DSM-IV-TR diagnosis of other psychotic disorders seek early psychiatric treatment about $82 \% \quad(\mathrm{AOR}=0.18$, 95\% CI 0.06 to 0.51 ) more than patients with bipolar disorder. Participants who came after seeking religious treatment were 3.7 times (AOR=3.73, 95\% CI 1.75 to 7.96 ) more delayed than patients who came directly to psychiatric service. Participants who perceived mental illness as shameful were 3.4 times (AOR=3.42, 95\% CI 1.19 to 9.83) more likely to have delayed psychiatric treatment than those who perceived it as not shameful (table 5).

\section{DISCUSSION}

Data on the DSM-IV-TR diagnoses of participants in this study indicated that schizophrenia accounts for $43 \%$, major depressive disorder $20.1 \%$, other psychotic disorders $18.7 \%$, bipolar disorders $10.9 \%$, anxiety disorders $13.8 \%$ and epilepsy $1.4 \%$.
Data on the pathway to psychiatric care of the study participants revealed that $71.4 \%$ first sought help from religious sources and 2.6\% from traditional healers. Less than a quarter $(22.5 \%)$ sought direct psychiatric treatment and $3.5 \%$ participants sought help from general health practitioners. This is in agreement with the results of a study from Nigeria which reported that most of the participants first sought treatments from religious and traditional healers $(76.8 \%)$. Psychiatrists were the first contact for $18.5 \%$ of participants, while $4.6 \%$ received medical attention from general practitioners. ${ }^{11}$ Similar results were also reported in another Nigerian study which indicated that many individuals sought treatments first from religious healers (48\%), followed by traditional healers (20\%), general/private hospitals (20\%) and lastly psychiatric hospitals $(12 \%) .{ }^{12}$ Results from a study in India also showed that faith healers $(39.5 \%)$ followed by nonpsychiatrist allopath care providers (29\%) were the most consulted sources of help. Direct contact with psychiatric treatment was reported by $13.5 \%$ of patients. ${ }^{6}$ However, these contradict the results of studies from Ghana and Ethiopia. A Ghanaian study showed that $52.3 \%$ of patients first sought care at psychiatric hospitals; another 23.3\% sought care from religious or traditional healing centres as their first contact; $21.5 \%$ sought treatment from nonpsychiatric general hospitals as first point of contact; and $2.9 \%$ sought help from community health nurses and other community medical practitioners as their first contact of mental healthcare. ${ }^{16}$ In one of the Ethiopian studies, over a third of the patients $(35.2 \%)$ came directly to psychiatric treatment. Half of the patients sought traditional treatment from either a religious healer $(30.2 \%)$ or a herbalist $(20.1 \%)$ before they came for psychiatric treatment. ${ }^{17}$ In another Ethiopian study it was shown that $41 \%$ directly consulted a psychiatrist, $30.9 \%$ sought help from holy water/church, $21.5 \%$ consulted doctors and $4.5 \%$ had initial contact with a herbalist. ${ }^{10}$ The differences could be due to study area and sample size. Studies done in capital cities have larger proportions of patients using direct psychiatric treatment, which could be associated with accessibility of mental health services and higher literacy, whereas sample size could also play a significant role as studies used different sample sizes ranging from 107 to $1044 .^{1016}$

The prevalence of delayed psychiatric treatment was $176(41.6 \%)$. It was lower than a study conducted to assess patterns of treatment-seeking behaviour for mental illnesses in Southwest Ethiopia in which the reported treatment delay was $65.1 \% .^{17}$ This might be due to the current study being conducted 7 years after the previous study and patients and their relatives might have relatively better awareness about mental illness and treatment options. The median DUMI from illness onset to first carer contact and first psychiatric treatment contact was 4.0 and 52 weeks, respectively. Different studies also indicated similar pathways taken to seek help in majority of PMI, as well as similar median DUMI to first psychiatric treatment $(6,11,12$, and 17$)$. However, the median 
Table 5 Multivariate analysis of factors associated with delayed psychiatric treatment at Ayder Comprehensive Specialized Hospital, July 2017 ( $N=423)$

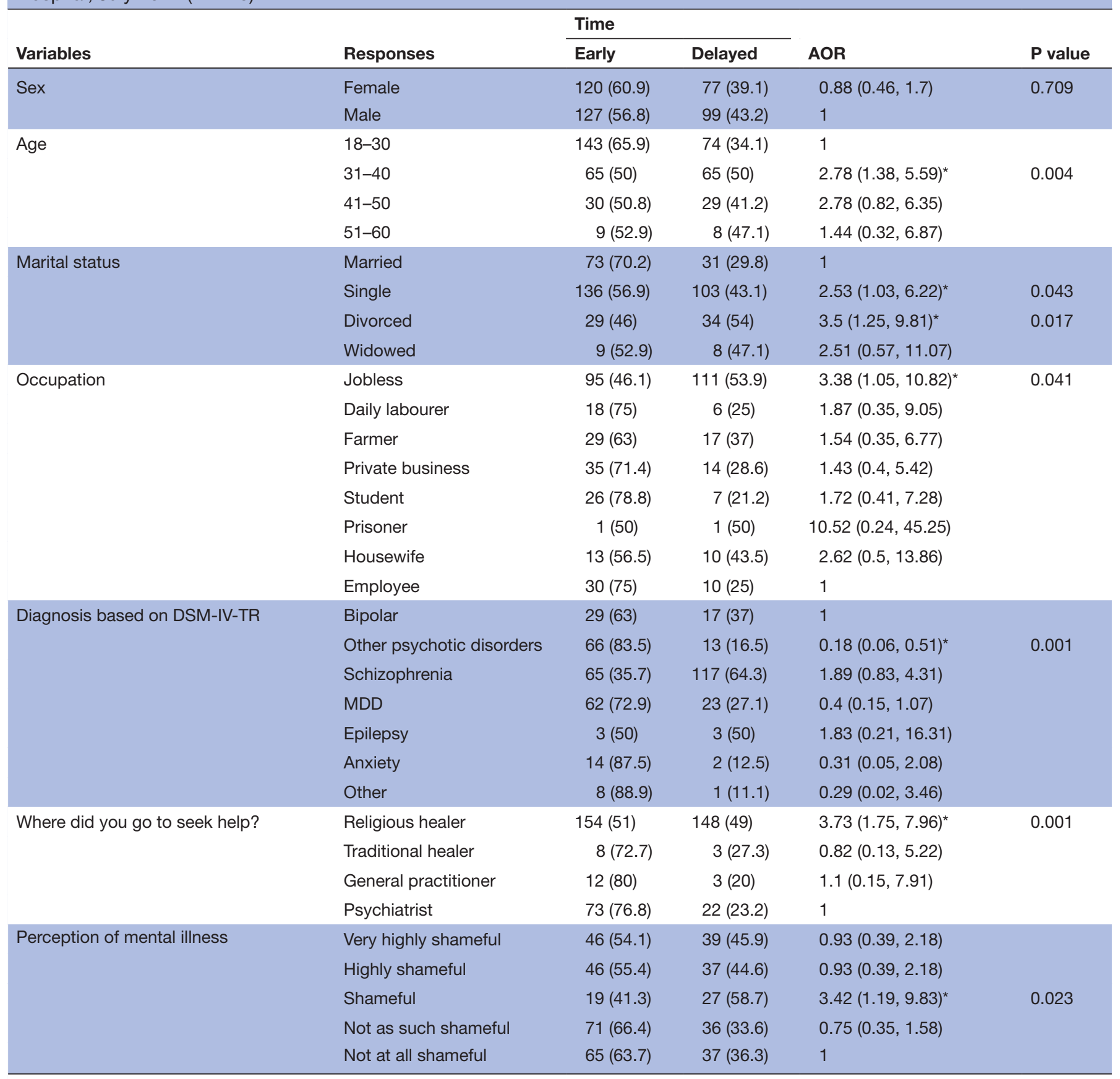

* =statistically significant

AOR, adjusted OR; DSM-IV-TR, Diagnostic and Statistical Manual of Mental Disorders, Fourth Edition, Text Revision; MDD, Major depressive disorder.

DUMI was less than a study from Pakistan ${ }^{14}$ and greater than studies conducted in Iran, Bangladesh and Ethiopia $(10,13$ and 15). Probable reasons for this discrepancy could be the small sample sizes in the Pakistan ( $\mathrm{n}=93)$ and Bangladesh $(\mathrm{n}=50)$ studies and the clinical diagnosis of the study population, in which the Pakistani study employed only patients with psychosis. Other possible reasons could be sociocultural differences among the study participants and different healthcare set-ups.
In this study majority $(59.6 \%)$ of the participants who sought treatment for their illness were on the advice of family/relatives, whereas $28.1 \%$ were advised by former patients, $7.6 \%$ managed to come by themselves, and $74.7 \%$ came without referral letters. Closely similar results were obtained from a study in the Ethiopian capital, where majority $(69.6 \%)$ of study participants attended to psychiatry on the advice of their family, $9.4 \%$ on the advice of former patients and $87.6 \%$ came without any referral. ${ }^{10}$ 
This is because most patients in Ethiopia get support and care from their family/relatives. Similar results were also found from other studies in which reasons for accessing mental health service were due to advice from friends and close relatives in about $64 \%$ of patients. This mostly have happened after patients' illness has worsened. ${ }^{11}{ }^{12}$ This is a crucial area for emphasis, and attention should be given to providing peer support to PMI. Service users and researchers in developed countries have strongly advocated for access to peer support for people with $\mathrm{SMI}^{20}$ and went further to implementation of the peer support network interventions. ${ }^{21} \mathrm{~A}$ systematic review conducted in lowincome and middle-income countries also showed positive results from peer-delivered interventions. ${ }^{22}$ Therefore, it is vital to use these resources in interventions to hasten early psychiatric treatment for PMI.

The stigma associated with mental illness was found to affect preferences for sources of help among patients and caregivers. In this study about $24.1 \%$ of the study participants responded that the problems faced in the help-seeking process were due to family members feeling ashamed of their illness. In a study from Pakistan, almost $25 \%$ of the mentally ill patients and an equal number of family members reported that they felt shy in discussing their illness. ${ }^{11}$ A study from Nigeria indicated that $20 \%$ of PMI were influenced by stigma and discrimination with regard to seeking specialist care. ${ }^{12}$ It is very crucial to provide intervention on this aspect as the stigma encountered by an individual might be a significant barrier to helpseeking behaviour, resulting in delayed psychiatric care. This study revealed reasons for delay in help-seeking were due to distance $(8.5 \%)$ and financial difficulties $(9.7 \%)$, whereas $52.5 \%$ reported they did not know where to seek help, $17 \%$ due to lack of availability of mental health facilities near their area, and $5.9 \%$ did not believe on modern treatment. With regard to problems faced with help-seeking process, $64.3 \%$ were due to family members not recognising the severity of illness, $3.8 \%$ could not convince the medical staff of the severity of the illness, and $2.6 \%$ were discouraged by relatives/friends from seeking help. This study is similar with the study done in Pakistan where participants were enquired about the reasons for delay; around $29 \%$ reported financial difficulties, $16 \%$ cited difficulties in reaching treatment centres, while $40 \%$ of patients and $9 \%$ of family and friends did not feel the need for treatment. In around $23 \%$ of cases, the patients and their family did not have information regarding centres that offer treatment. Around $5 \%$ of the cases reported that healthcare providers did not take the illness seriously. ${ }^{11}$ This similarity might be due to lack of availability of mental service, lack of awareness and mental health literacy in psychiatric services, and lack of integration of mental health with mainstream health services in these study areas. In Nigeria also about $20 \%$ mentioned lack of available mental health services in the community as the reason for delays in seeking early treatment. The rest $(80 \%)$ indicated that poor awareness about mental health services related to traditional beliefs regarding the causes of mental health, with health services not considered a priority for treatment of such illnesses. ${ }^{14}$ This similarity might be due to lack of availability of mental health service, lack of awareness and mental health literacy in psychiatric services, and lack of integration of mental health with mainstream health services in these countries. With regard to perceptions and beliefs about the cause of mental illness, the study participants responded that their perceived causes of mental illness were spiritual possession $(124,29.3 \%)$, evil eye $(41,9.7 \%)$, sinful act $(31,7.3 \%)$, do not know (32, 7.6\%) and walks around garbage dumps $(38,9 \%)$. In Southwest Ethiopia, the most common explanations given for the cause of mental illness were spiritual possession $(198,51.6 \%)$ and evil eye $(61,15.9 \%)$, whereas $73(19.0 \%)$ respondents said they did not know the cause of mental illnesses. ${ }^{8}$ The study done in Nigeria showed $20 \%$ believed that mental health issues were caused by charms from an enemy or supernatural powers. This similarity might be due to lack of awareness on the cause of mental illness in these study areas.

Study participants who came after seeking religious treatment were 3.8 times more likely to delay psychiatric treatment than those who came directly to psychiatric treatment. This is because consulting healers first might lead to prolonged pathway to psychiatric care and can be an obstacle to early detection, identification and intervention. ${ }^{6} 1518$ Participants who were single and divorced were 2.5 and 3.5 times more likely to delay compared with those who were married. However, it is reported that participants who chose to use psychiatric services as the first point of care were more likely to be unmarried. This inconsistency might be due to lack of social support. Study participants who were jobless were 3.4 times more likely to delay treatment compared with employed participants. In this study the 31-40 years age group had significant statistical association with delayed treatment-seeking behaviour compared with the 18-30 years age group. In studies conducted at Amanuel Mental Specialized Hospital in Ethiopia, unemployment was found to be associated with delayed treatment-seeking behaviour, but there were no significant associations between duration of delay on pathway to care and age group and marital status. ${ }^{4}$ This might be due to lack of economic support in getting modern treatment that necessitates long distance travel due to inaccessibility. With regard to patient diagnosis and treatment-seeking behaviours, patients with a diagnosis of other psychotic disorders sought psychiatric treatment $80 \%$ earlier than patients with bipolar disorder. The probable reason could be the clinical presentation of the illness, in which patients of this category are affected by more psychotic phenomena, resulting in a relatively overt behavioural disturbance than patients with bipolar disorder.

\section{Strengths and limitations of the study}

This is a study on pathway to care that portrays the paths taken by patients with mental illnesses to arrive at a psychiatric care facility. It indicates the various intermediate sources of help that patients used before a visit for psychiatric care. Regardless of patients' perceived importance, 
the intermediate sources of help play a role in the duration of use of psychiatric treatment, and the current study identified sources of help that contributed to delayed psychiatric treatment. Additionally, the study also assessed patient-related factors, illness perception and stigma among others that affect delayed psychiatric care. However, the study did not assess the use of other sources of help post psychiatric care treatment that might have an impact on treatment adherence. Recall bias on the first onset of illness and/or the duration of illness could be a major limitation as majority might know the exact time and used only approximations. The use of intervieweradministered questionnaire might have contributed to social desirability bias and selection of participants from a single facility, which were other limitations of this study.

\section{CONCLUSIONS}

The results of the study showed a significant delay in seeking modern psychiatric treatment. Religious healers were the first source of help for mental illness. Most of the respondents described that mental illnesses were caused by supernatural causes. First contact with religious sources of help, unmarried status, jobless/unemployed status, being in the 31-40 years old age group and patient diagnosis of other psychotic disorders were significantly associated with delayed psychiatric treatment. Therefore, it is vital to provide interventions for factors that played a role in delayed psychiatric treatment.

Acknowledgements We would like to acknowledge Jimma University for the financial support to facilitate the study. We are very grateful to the data collectors and participants for their precious input in the study process. We would like to thank Professor Markos Tesfaye for his contribution to study design and for his invaluable feedback from the commencement of the study to the reporting of study results.

Contributors ST designed the study and was involved in the data collection, analysis and write-up. $\mathrm{HK}$ and $\mathrm{HH}$ were involved in the design and data analysis and drafted the manuscript. MA participated in the design of the study and analysis of data and critically reviewed the manuscript. All authors read and approved the final manuscript.

Funding The authors have not declared a specific grant for this research from any funding agency in the public, commercial or not-for-profit sectors.

Competing interests None declared.

Patient consent for publication Not required.

Ethics approval Ethical clearance was obtained from the College of Medicine and Health Science's Institutional Research Review Board (IRB) of Jimma University. Written informed consent was obtained from study participants, confirming willingness to participate after explaining the objective of the study. The information provided by each respondent was kept confidential.

Provenance and peer review Not commissioned; externally peer reviewed.

Data availability statement Data are available upon reasonable request to the corresponding author (email: habtaishk@gmail.com).

Open access This is an open access article distributed in accordance with the Creative Commons Attribution Non Commercial (CC BY-NC 4.0) license, which permits others to distribute, remix, adapt, build upon this work non-commercially, and license their derivative works on different terms, provided the original work is properly cited, appropriate credit is given, any changes made indicated, and the use is non-commercial. See: http://creativecommons.org/licenses/by-nc/4.0/.

ORCID iD

Habtamu Kerebih http://orcid.org/0000-0002-0656-7716

\section{REFERENCES}

1 Fridell M, Bäckström M, Hesse M, et al. Prediction of psychiatric comorbidity on premature death in a cohort of patients with substance use disorders: a 42-year follow-up. BMC Psychiatry 2019;19:150.

2 Walker ER, McGee RE, Druss BG. Mortality in mental disorders and global disease burden implications: a systematic review and metaanalysis. JAMA Psychiatry 2015;72:334-41.

3 Kessler RC, Amminger GP, Aguilar-Gaxiola S, et al. Age of onset of mental disorders: a review of recent literature. Curr Opin Psychiatry 2007;20:359-64.

4 Wang PS, Angermeyer M, Borges G, et al. Delay and failure in treatment seeking after first onset of mental disorders in the world Health organization's world mental health survey initiative. World Psychiatry 2007;6:177.

5 Trivedi JK, Jilani AQ. Pathway of psychiatric care. Indian J Psychiatry 2011;53:97.

6 Jain N, Gautam S, Jain S, et al. Pathway to psychiatric care in a tertiary mental health facility in Jaipur, India. Asian J Psychiatr 2012;5:303-8.

7 Jilani A, Trivedi J. Pathways of care of psychiatric patients in South Asia. South Asian J Psychiatry 2011;2:29-41.

8 Bhui K, Ullrich S, Coid JW. Which pathways to psychiatric care lead to earlier treatment and a shorter duration of first-episode psychosis? BMC Psychiatry 2014;14:72.

9 Daisuke F, Naoki H, Yayoi K, et al. Multicenter collaborative study on pathway to psychiatric care: a pilot study in Japan. Clin Psychiatry 2007;49:7-15.

10 Bekele YY, Flisher AJ, Alem A, et al. Pathways to psychiatric care in Ethiopia. Psychol Med 2009;39:475-83.

11 Effiong J, Albert U. Pathways to psychiatric care among patients with schizophrenia in Uyo, Nigeria. Int Neuropsychiatr Dis J 2016;5:1-10.

12 Jack-Ide I, Makoro B, Azibiri B. Pathways to mental health care services in the niger delta region of Nigeria. $J$ Res Nurs Midwifery 2013;2:22-9.

13 Sharifi V, Kermani-Ranjbar T, Amini H, et al. Duration of untreated psychosis and pathways to care in patients with first-episode psychosis in Iran. Early Interv Psychiatry 2009;3:131-6.

14 Naqvi HA, Hussain S, Zaman M, et al. Pathways to care: duration of untreated psychosis from Karachi, Pakistan. PLoS One 2009;4:e7409.

15 Giasuddin NA, Chowdhury NF, Hashimoto N, et al. Pathways to psychiatric care in Bangladesh. Soc Psychiatry Psychiatr Epidemiol 2012;47:129-36.

16 Ibrahim A, Hor S, Bahar OS, et al. Pathways to psychiatric care for mental disorders: a retrospective study of patients seeking mental health services at a public psychiatric facility in Ghana. Int J Ment Health Syst 2016;10:63.

17 Girma E, Tesfaye M. Patterns of treatment seeking behavior for mental illnesses in Southwest Ethiopia: a hospital based study. BMC Psychiatry 2011;11:138.

18 Hashimoto N, Fujisawa D, Giasuddin NA, et al. Pathways to mental health care in Bangladesh, India, Japan, Mongolia, and Nepal. Asia Pac J Public Health 2015;27:NP1847-57.

19 World Health organization: WHO pathways to care 2006.

20 Faulkner A, Basset T. A helping hand: taking peer support into the 21st century. Mental Health and Social Inclusion 2012;16:41-7.

21 Ibrahim N, Thompson D, Nixdorf R, et al. A systematic review of influences on implementation of peer support work for adults with mental health problems. Soc Psychiatry Psychiatr Epidemiol 2020;55:285-93.

22 Vally Z, Abrahams L. The effectiveness of Peer-Delivered services in the management of mental health conditions: a meta-analysis of studies from low- and middle-income countries. Int J Adv Couns 2016;38:330-44. 